\title{
Recommendations for publishers of conference proceedings
}

\author{
Prepared by the ACRL Science and Technology Section
}

\section{Recommendations developed in 1986 by the ACRL Task Force on Conference Proceedings.}

I n 1984 the ACRL Science and Technology Section formed an ad hoc Committee on Designing a Conference Proceedings Style Sheet. Committee members included Dorothy McGarry (chair), Grace Agnew, Carol Cubberley, Edward Garten, and Sara Shatford Layne.

Given the problems found in cataloging and identifying conference proceedings, the committee thought it would be useful to prepare recommendations that will assist editors and publishers in the preparation of proceedings for publication. A draft of these recommendations appeared in the February 1986 issue of C $\mho R L$ News. Based on feedback from ACRL members, the Committee revised the draft. The STS Executive Committee approved the draft in January 1987 and reaffirmed their approval in January 1989.

\section{Recommendations}

Published proceedings of conferences are very important in research. It is often difficult, however, for people to locate the proceedings of a particular meeting. Often the title pages of these proceedings are confusing in their layout, or the title pages contain insufficient information for identifying a particular conference. This is critical because the title page is the established standard source for information used to catalog a book. The librarians who catalog the book and the library users who request it may not be sure what the title is intended to be, or who published the book, or even what the name of the meeting is. This confusion and uncertainty make it difficult for library users to know how to cite the book or how to look for it in a catalog.

Those who prepare and publish conference proceedings could contribute to the usefulness of the conference literature by applying the following guidelines:

\section{Title page}

The title page should include:

A clearly indicated title.

Examples:

Microcomputer software.

Modern problems of surface physics.

Clearly indicated information beyond that of the title itself, including information such as the name of the meeting if it had a name.

Example:

Proceedings of the Working Conference on Circulation, Neurobiology, and Behavior, held October 4-7, 1981, in Dallas, Texas, U.S.A.

The relationship of the book to the conference should be indicated on the title page.

Examples:

Proceedings of the 23rd IEEE Conference on Decision \& Control.

Selected papers from the Workshop on ...

Layout and typography can assist in identifying the various elements of information required.

Include the number of the meeting if any, and the place and date the meeting was held.

Name of sponsoring organization(s), with an explicit statement such as "sponsored by" or "organized by."

An explicit description of function with the 
name(s) of the editor(s), such as "edited by," or "chairman/editor."

Series statement, if the publication is part of a series, with clearly indicated series title and numbering.

Place(s) of publication, name(s) of publisher(s), and date(s) of publication.

Confusion can arise depending on how information appears on the title page; i.e., the initials of the conference may appear at the top of the page followed by the name of the conference or "Proceedings of the ..." followed by words which might actually be the book's title meant by the publisher or the editor. A library may choose a title the publisher or editor didn't intend when describing the book in a catalog, not being sure which of the parts was meant to be the title. The library user may come up with two different citations for the same conference, perpetuating problems in retrieval. As an example:

Proceedings of the Workshop on Geological Disposal of Radioactive Waste (top of page).

In Situ Experiments in Granite (middle of page).

This might result in one cataloger putting as the title "Proceedings of the ..." and another using "In situ experiments in granite." In this case, the title on the front cover was "Geological disposal of radioactive waste," which could add to the confusion over what the title was meant to be.

All information on the title page should be consistent with information on the cover and spine; titles should not differ from cover to title page, nor should the name of the meeting nor the title of the series differ from location to location within the book.

\section{Back of the title page}

The back of the title page should include:

Name and address of distributor, if different from publisher, with an explicit statement of function; e.g., "distributed in the U.S. by," or "available from."

Copyright information.

\section{Miscellaneous}

\section{Names of conferences:}

Catalogers attempt to determine, when checking a conference publication, whether the conference is "named" or "unnamed." A book whose title page reads Semiconductor physics: Proceedings of an International Conference would not be considered to be the proceedings of a "named" conference while Proceedings of the International Conference on Semiconductor Physics would lead to access under the name "International Conference on Semiconductor Physics." In the first case, "an international conference" is taken to be a purely generic description; in the second case, "the International Conference on ..." indicates a specifically named event.

In cases where different forms of a conference name appear in different locations, the cataloger must determine whether the name of the conference might be, for example:

Computer Society Conference on Artificial Intelligence Applications (title page)

Conference on Artificial Intelligence Applications (cover)

IEEE Computer Society Conference on Artificial Intelligence Applications (preface)

While in some situations this might not matter much, in putting a record for this work into a catalog for patrons' and librarians' use it is important to remember that the record could appear in any one of three different locations in the catalog. Furthermore, if the conference is one in a series of similar conferences, and each year there is a change in the order of the words in the name, such as Condensed Matter Physics Symposium: Symposium on Condensed Matter Physics, the records for these conferences will not appear next to each other in the catalog and the works will not appear next to each other on the shelves.

The name of the conference, if it has one, should appear clearly on the title page, back of the title page, pages before the title page, the cover, or the spine, in order for provision of clear and primary access to that name in bibliographic records; librarians would appreciate it if it actually appeared on the title page. If the name of the meeting does not appear in any of the places mentioned above, access to the name of the conference on a record would depend on whether the cataloger noticed the name elsewhere (e.g., in the preface or introduction) and whether a note and an additional access point were made. Of course, if the meeting has no name as far as the conference arrangers are concerned, it is not necessary to create one.

If a name is used for the conference it should be the same in all locations in the book.

If a name of a conference changes from one meeting to the next, and the intent is that they be considered to be related (e.g., earlier and later name of conferences in a sequence) indicate in the later publication that the name of the previous meeting was different.

Names of corporate bodies:

If the name of a corporate body is placed on the title page, provide with it some explanation of the relationship of that body to the conference or to the publication, e.g., "published by," "sponsored by," "organized by," "supported by."

Numbering:

If a conference is given a number, and previous 
conferences in the sequence had no number, provide a list of the conferences, with title, name of conference (if different), and date and where held, so that related conferences can be referred to or linked through cross references.

If conferences are numbered, and the proceedings of a particular conference are not published, provide that information in a later volume.

Number the pages consecutively, if possible.

"Volume" and "edition" have very specific meanings In libraries. "Volume 2," e.g., should not be used for the proceedings of the second conference in a sequence. "Volume" should be used only if the proceedings of a particular conference are published in two or more physical volumes. A statement that calls something a "second edition" should refer to the same text reworked or reset, not to totally new text. Proceedings of a second conference would not, therefore, be either a "second edition" or a "volume two" of the first conference.

Although librarians are among the primary collectors of conference proceedings, catalog records for these proceedings appear in machine-readable databases which make the information available to millions of library users. Proper access to these proceedings makes them more valuable to the scientific, academic, and business communities. With the help of those who prepare and publish conference proceedings library users will be able to locate and use those proceedings more efficiently.

\title{
The 1990 Annual Conference of
}

\section{German Librarians}

\author{
By Siegfried Feller \\ Chief Bibliographer \\ University of Massachusetts
}

Expectations and speculation in the Saarland.

he 80th conference of German [Academic/Research] Librarians (Bibliothekartag) was held June 5-8, in Saarbrücken, capital of the Saarland, a state adjacent to Luxembourg and near the French city of Metz. The primary host institution was the University of Saarland; it lies a few miles outside the city, but is well-served by municipal buses. All open sessions, except for the formal opening ceremonies, were held on campusmostly in a building near the library.

The Verein Deutsche Bibliothekare (VDB) and the Verein deutscher Diplom-Bibliothekare (VdDB) are the chief sponsors of each annual conference, and this year, for the first time, the annual meeting of the German Library Association
(Deutscher Bibliotheksverband, DBV) was held in conjunction with the Bibliothekartag-the U.S. analogy would be if the annual ARL meeting were held at the same place and time as ALA Annual Conference. Also participating (for the second or third time) was the Association of Library Support Staff (Bundesverein der Bibliothekassistenten/innen, BBA).

"Libraries in Europe" was the theme of this year's conference, and the new president of the VDB, Engelbert Plassman (rector of the Professional School for Librarianship and Documentation, Köln) made a considerable effort to attract professional colleagues from other countries. An unusually large percentage of these visitors deliv- 